\section{SP0094 THE SWEDISH EXPERIENCE - HOW A PATIENT ORGANISATION COULD REACH OUT TO IMMIGRANTS AND DEVELOP} THROUGH INTEGRATION

T. Diao. The Swedish Rheumatism Association (SRA), Stockholm, Sweden

Bakground: in the early years of the new millennium many European countries faced an increased number of immigrants due to the second Iraqi war that affected the whole sub region. Some of these immigrants reached the Swedish shores and many of them have RMDs.

In an attempt to help integrate them to the Swedish society, the SRA reached out to these immigrants with RMDs to give them the tools and the knowledge of how to live a decent life with RMDs and also to inform them about how the Swedish healthcare system works. By informing them and giving them the tools to live their lives to the fullest in Sweden the SRA participated indirectly to reduce the burden of the welfare system and also increased the number of our members and embraced the diversity in the organisation.

Objectives: By running some tests with our local chapters the SRA noticed that the lack of knowledge about the RMDs was immense among these minorities. So the SRA decided to act together with other actors to facilitate the inclusiveness of these minorities into the society.

Methods: To achieve this giant task the SRA applied and received financial support from the Swedish General inheritance fund and collaborated with several health providers, the employment office, some Folk High Schools, ABF (Adult Liberal Education Association) and our local chapters and joinders in 5 of the biggest cities: Stockholm, Örebro, Gothenburg, Norrköping and Umeå.

Results: This experience was a breakthrough for the SRA. The SRA was the firth patient organisation that walked this new path. The iconoclastic experience enriched the SRA and gave it a great knowledge of how to reach out to minority groups and giving them the tools to be a fully part of the society despite the burden of the RMDs.

Conclusion: The SRA increased it's knowledge, capacity and flexibility during this experience. Today the SRA is cited as a reference in Sweden when it comes to reaching out to different minorities suffering of RMDs. Many organisations are now lining up to work with the SRA in these matters. In 2007 the SRA received the price for best project from the Swedish General Inheritance Fund.

Disclosure of Interest: None declared

DOI: 10.1136/annrheumdis-2017-eular.7298

\section{THURSDAY, 15 JUNE 2017 EULAR Projects in musculoskeletal imaging}

\section{SP0095 EULAR RECOMMENDATIONS FOR THE USE OF IMAGING IN THE DIAGNOSIS AND MANAGEMENT OF LARGE VESSEL VASCULITIS IN CLINICAL PRACTICE}

C. Dejaco ${ }^{1,2}$ on behalf of Taks force to develop the EULAR recommendations for the use of imaging in LVV. ${ }^{1}$ Rheumatology, Medical University Graz, Graz, Austria; ${ }^{2}$ Rheumatology Service, Hospital of Bruneck, Bruneck, Italy

Large vessel vasculitis (LVV) is the most common form of primary vasculitis comprising giant cell arteritis (GCA) and Takayasu arteritis (TA).

Although temporal artery biopsy and conventional angiography are still the golden standard diagnostic tests for GCA and TA, respectively, modern imaging methods including ultrasound, magnetic resonance imaging, computed tomography (CT) and ${ }^{18} \mathrm{~F}$-FDG positron emission tomography - CT are increasingly used. In clinical practice however, these methods are inconsistently applied and rheumatologists and other specialists are still uncertain about the specific value of these modalities. This project has been conducted with the aim to provide user-friendly, evidencebased recommendations for the use of modern imaging methods for diagnosis, monitoring and outcome prediction of primary LVV. Specifically, we give advice on 1) when to use these imaging techniques, 2) what specialists might conclude from imaging results and 3 ) what technical standards are required to achieve high quality imaging results.

These recommendations aim at an early and specific diagnosis as well as an improved assessment of LVV, thus ultimately leading to better outcomes of patients with LVV.

Disclosure of Interest: C. Dejaco Grant/research support from: Pfizer, MSD, Esaote, Speakers bureau: Pfizer, MSD, AbVie, Celgene, UCB, Roche, BMS, GSK, Novartis, Sandoz

DOI: 10.1136/annrheumdis-2017-eular.7221

\section{SP0096 EULAR/PRES STANDARDISED PROCEDURES FOR MUSCULOSKELETAL ULTRASOUND (MSUS) IMAGING IN PEDIATRIC RHEUMATOLOGY}

\section{P. Collado. Rheumatology, Hospital Universitario Severo Ochoa, Madrid, Spain}

Musculoskeletal ultrasound (MSUS) is a readily available and suitable imaging technique to asses the immature skeleton of paediatrics in different musculoskeletal rheumatic diseases (MSRD). Besides the potential operator-dependent feature of this technique, the age-related variation of normal sonoanatomy due to the child's growth makes more difficult acquisition, interpretation and comparison of images than in adults. Hence, to use MSUS as a valid technique for diagnosis of MSRD, it is needed to develop specifically evidence-based recommendations for paediatrics. Additionally, the variability in background and experience of ultrasonographers in different countries requires an international multidisciplinary contribution for an optimal standardization of MSUS performance in paediatric MSRD.

Reflecting the perceived need for developing recommendations on the standardization of procedures for performing MSUS examination in MSRD, a collaborative international EULAR/PReS task force was convened. In the talk, it is going to summarize the original proposed specific aims and update on work for each aim previously mentioned. A systematic literature search was performed in Medline and Embase from databases inception to 1st June 2016 as the first step. One hundred and eighty-eight articles were finally included after reviewing 6059 records identified. The scanning for the knee and the ankle joint was the most common reported, whereas the paediatric wrist was uncommon.

Disclosure of Interest: None declared

DOI: 10.1136/annrheumdis-2017-eular.7074

\section{SP0097 REPORT OF ANATOMY FOR THE IMAGE REPORT OF THE EULAR WORKING GROUP OF ANATOMY FOR THE IMAGE}

I. Möller on behalf of EULAR Working Group Anatomy for the IMAGE. Rheumatology; anatomy; sonoanatomy-sonopathology, Instituto Poal de Reumatología; University of Barcelona, Hospitalet de Llobregat, Spain

The EULAR Working Group for the Image became an official "working group" 2 years ago with the purpose of furthering anatomic study and education related to the human musculoskeletal system and relevant non-musculoskeletal structures important in the practice of rheumatology and, more specifically, rheumatologic imaging including but not limited the high-resolution musculoskeletal ultrasound and MRI.

Studies performed:

- "Sonographic and anatomical description of the subtalar joint" - submitted for publication.

- "The anterior rotator cuff - a link between anatomy and ultrasound" - submitted for publication.

- "Learning model for successful ultrasound-guided synovial biopsy": pending submission.

New/Ongoing projects:

- Deep layer of the abdominal subcutaneous fat pad and cardiovascular risk: ultrasound measurement and relationship with visceral fat

- The mechanical function of the Hoffa fat pad as seen in a dynamic musculoskeletal ultrasound study.

- Ultrasound study of the neurovascular supply to the joints.

- The relevance of ligaments in inflammatory disorders of the articulations of the hand and wrist.

- The principles of anatomy as seen in musculoskeletal ultrasound.

Activities promoted by the group:

- Barcelona Sonoanatomy IX and X under scientific endorsement of EULAR.

Support:

- OMERACT: "Reliability exercise of synovitis at the subtalar joint".

In collaboration with the University of Barcelona:

- Certificate Course "Expert in Musculoskeletal Ultrasound".

Disclosure of Interest: None declared

DOI: 10.1136/annrheumdis-2017-eular.7157

\section{THURSDAY, 15 JUNE 2017}

\section{Capillaroscopy I \& II}

\section{SP0098 THE IMPORTANCE TO DIFFERENTIATE NORMAL FROM ABNORMAL CAPILLAROSCOPIC IMAGES FOR AN EARLY DIAGNOSIS OF DISEASE}

V. Smith. Department of Rheumatology, Faculty of Internal Medicine, Ghent University Hospital, Ghent University, Gent, Belgium

Medical doctors frequently get patients with Raynaud's phenomenon (RP), a frequent symptom in the general population, referred. The importance of distinguishing normal capillaroscopic findings from (pathognomonic) abnormal (pathological) findings, lies in the fact that this distinction allows the differentiation between a primary RP (not connected to any connective tissue disease [CTD]) from a secondary RP due to systemic sclerosis (SSc) and diseases of the scleroderma spectrum.

What is normal in primary RP? A normal capillaroscopic pattern, by qualitative assessment, is characterized by a homogeneous distribution of hairpin shaped capillaries as a "comb-like structure", with a density of between 9-14 capillaries per $\mathrm{mm}$. Yet, there exists a wide intra- and inter-individual variety in a normal population which will be discussed in this session.

What is pathognomonic abnormal in patients with RP due to SSc? Patients with the RP who have an underlying clinically recognizable (= with skin involvement) SSc show a very characteristic combination of capillary abnormalities in the nailfold, which can easily be assessed through qualitative assessment (= pattern 
recognition). Maricq et al. described last centrury, with the widefield technique (magnification $\mathrm{X} 12-14$ ) the scleroderma pattern. This pathognomonic combination contains the following: a striking widening of all three segments of the capillary loop (arterial, venous and intermediate), loss of capillaries, disorganization of the nailfold capillary bed. Many branched "bushy" capillaries may also be observed. In 2000, Cutolo et al. qualitatively assessed the nailfolds of an SSc cohort with patients fulfilling the American College of Rheumatology (ACR) criteria for SSc with the nailfold videocapillaroscopic (NVC) technique (magnification X200). According to the different proportions of the hallmark parameters of the scleroderma pattern (giants, capillary loss, hemorrhages and (neo)angiogenesis Cutolo et al. defined three patterns "early", "active" and "late".

The central role of capillaroscopy in distinction between a primary and secondary RP due to SSc is reflected by the fact that capillaroscopy is one of the new ACR/EULAR criteria for classifying a patient as having SSc.

Besides playing a paramount role in distinguishing a primary from secondary RP, capillaroscopy has an additional role. It can inform the rheumatologist dealing with a patient population with merely the RP and no other signs of a CTD, who will futurely develop SSc. This role is reflected by capillaroscopy playing a central role in the LeRoy and VEDOSS criteria for (very) early diagnosis of SSc.

What about capillaroscopic morphology in connective tissue diseases other than SSc?

No large scale prospective cohorts exist describing capillaroscopic morphology in connective tissue diseases other than SSc. Moreover, several morphologic defintions exist across literature of different schools. The EULAR Study Group on microcirculation in Rheumatic diseases was set up in 2014 to tackle, in between others these working points.

Disclosure of Interest: None declared

DOI: 10.1136/annrheumdis-2017-eular.7161

\section{SP0099 WHY CAPILLAROSCOPY CAN PREDICT DISEASE SEVERITY AND PROGNOSIS}

M. Cutolo on behalf of EULAR Study Group on Microcirculation. Internal Medicine, Research Lab Division Rheumatology University of Genova, genova, Italy

Nailfold capillaroscopy (NVC) is today considered to be safe biomarker in order to make an early diagnosis of slected Connective Tissue Diseases (CTDs) in presence of Raynaud' phenomenon, and to measure progressive microvascular and tissues damage including response to long term treatment,

Systemic sclerosis is the only CTD to date in which prognostic indices have been described to predict clinical complications. Predictions have been made based on baseline capillaroscopic images and based on sequential capillaroscopic follow-up.

Baseline qualitative-assessed scleroderma patterns have been described to be linked with future organ involvement in any of the nine organ systems affected by SSc according to the disease severity scale of Medsger (general, peripheral vascular, skin, joint, muscle, gastrointestinal tract, lung, heart and kidney) (1). Additionally, baseline capillaroscopic evaluations have been linked to future development of digital trophic lesions in SSc. A simple scoring system has been used recently in the largest pan-European study evaluating the role of capillaroscopy in predicting digital ulcers in SSc (2). More specifically, in this study, simply the number of capillaries per linear $\mathrm{mm}$ had been evaluated. Besides counting the number of capillaries/capillary alterations, dimensions can also be measured. The latter has also been used in prediction of patients with RP whether, because of SSc, there will be a possibility for them to develop a secondary RP. Similarly, it has recently been attested that if the average capillary diameter (average of the largest apical, efferent and afferent limb in 16 fields, more specifically 2 fields per finger, fingers $2-5$ from each hand) is less than $30 \mu \mathrm{m}$ in a group of patients with RP but without scleroderma characteristic findings on nailfold videocapillaroscopy (NVC), the patient has a low chance of developing SSc, while if $>30 \mu \mathrm{m}$, then the patient has $50 \%$ chance to develop SSc (3). Concerning the ability of capillaroscopy to measure response to treatment, there are yet no prospective randomized, double-blind, placebo-controlled trials, evaluating the ability of capillaroscopy to monitor response to therapy concerning RP-related outcome measures. It is noteworthy and promising that in small studies showing response of immunosuppressive/vasomodulating treatment on disease severity, outcome measures are available (4-6).

References:

[1] V. Smith et al. J Rheumatol 40,2013,52-7.

[2] M. Cutolo et al. Arthritis Rheumatol 68,2016,2527-39.

[3] A. Trombetta et al. J Rheumatol 43,2016, 599-606.

[4] I. Miniati et al. Ann Rheum Dis 68, 2009;94-8.

[5] V. Smith et al. J Rheumatol 43, 2016,995-6 6.

[6] A. Trombetta, C et al. J Rheumatol. 2016;43:2033-41.

Disclosure of Interest: None declared

DOI: 10.1136/annrheumdis-2017-eular.7295

\section{SP0100 HOW TO SELECT THE MOST APPROPRIATE CAPILLAROSCOPIC DEVICE: PROS AND CONS}

W. Hermann. Department of Rheumatology and Clincial Immunology, Kerckhoff-Klinik, Bad Nauheim, Germany

One of the most important indications for performing capillaroscopy is to differentiate between primary and secondary Raynaud's syndrome. Different kinds of microscopes are at hand and generally vary in terms of picture quality or price. Before purchasing a microscope and capillaroscopy software, several considerations about the required standards of examination should be made; some of which are summarized as follows:

- The region of interest (ROI). Normal capillaries have a mean diameter of about $8 \mu \mathrm{m}$. For an accurate assessment a magnification of 100-200x is recommended, for an overview the magnification of 50x is sufficient.

- Measurement. Beside qualitative measures like changes in vessel architecture, there should be the possibility of quantifying the number of capillaries $/ \mathrm{mm}$ or vessel diameters.

- Documentation. All parts of the examination have to be stored and assigned to patient and case.

- Practical aspects and handling of the device.

- Different kinds of microscopes are on the market of which three will be discussed in detail. Briefly summarized:

- Stereo microscopes.

Advantages: Very good image quality, zooming in and out without problems, relatively easy to use.

Disadvantages: device is not mobile, in patients with finger contractures examinations are difficult to perform, relatively high costs.

- Videocapillaroscopes:

Advantages: Very good image quality, easy to use, "gold standard" for capillaroscopy.

Disadvantages: No overview, zooming in and out not applicable (change of lenses required), relatively high costs.

- USB microscopes:

Advantages: low costs, zooming in and out without problems, easy to use.

Disadvantages: limited picture quality, documentation laborious.

Selecting a capillaroscopic device depends on the conditions of use ("quick look" vs. "academic evaluation and follow up"), which should be clarified before buying a device. The price range is significant and usually differs between $100 €$ for USB microscopes and up to $10,000 €$ for stereo and videocapillaroscopes

Literature:

[1] Cutolo $M$ et al. How to perform and interpret capillaroscopy. Best Pract Res Clin Rheumatol. 2013;27(2):237-48.

[2] Cutolo $M$ et al. State of the art on nailfold capillaroscopy: a reliable diagnostic tool and putative biomarker in rheumatology? Rheumatology (Oxford). 2013;52(11):1933-40.

Disclosure of Interest: None declared

DOI: 10.1136/annrheumdis-2017-eular.7206

\section{THURSDAY, 15 JUNE 2017 \\ Ultrasound, clinical, diagnostic and therapeutic skills I \& II}

\section{SP0101 DIAGNOSTIC AND THERAPEUTIC ULTRASOUND-GUIDED PROCEDURES}

P. Mandl. Rheumatology, Medical University of Vienna, Vienna, Austria

The lecture will provide an overview of sonography-guided musculoskeletal interventions which can be grouped broadly as diagnostic and therapeutic procedures. Primarily diagnostic procedures include arthrocentesis, biopsy from various musculoskeletal tissues (synovial, bone, muscle etc.), aspiration of fluid from cystic lesions, tendon sheaths and bursae. The therapeutic group features joint and soft tissue injections, needling of periarticular calcification, including barbotage. Both indirect and direct-guidance techniques will be detailed and published literature on accuracy, outcome and safety of sonographic-guided interventions will be reviewed.

Disclosure of Interest: None declared

DOI: 10.1136/annrheumdis-2017-eular.7272

\section{SP0102 HOW TO PERFORM A QUICK AND EFFICIENT PHYSICAL EXAMINATION}

M. Doherty. Academic Rheumatology, University of Nottingham, Nottingham, United Kingdom

The GALS (Gait, Arms, Legs, Spine) screen is a quick and reasonably sensitive way to detect common musculoskeletal (MSK) abnormalities as part of a general medical assessment (1). However, for a person with MSK complaints a detailed assessment is required to determine the diagnosis and the impact of the condition on that person. The key starting point is the history. This needs to be holistic and individualised as the enquiry proceeds since the impact of any condition is 